\title{
A Review: Mealtime Difficulties following Frontotemporal Lobar Degeneration
}

\author{
Courtney Lewis $^{a} \quad$ Mark Walterfang ${ }^{b-d}$ Dennis Velakoulis ${ }^{b, c}$ \\ Adam P. Vogel ${ }^{a}, e, f$
}

${ }^{a}$ Centre for Neuroscience of Speech, The University of Melbourne, Melbourne, VIC, Australia; ${ }^{b}$ Neuropsychiatry Unit, Royal Melbourne Hospital, Melbourne, VIC, Australia; 'Melbourne Neuropsychiatry Centre, The University of Melbourne, Melbourne, VIC, Australia; ${ }^{\text {d}}$ Florey Institute of Neuroscience and Mental Health, Melbourne, VIC, Australia; e Department of Neurodegeneration, Hertie Institute for Clinical Brain Research, University of Tübingen, Tübingen, Germany; ${ }^{f}$ Redenlab, Melbourne, VIC, Australia

\section{Keywords}

Frontotemporal dementia - Neurodegeneration - Dysphagia - Eating behavior - Primary progressive aphasia · Corticobasal degeneration - Progressive supranuclear palsy

\begin{abstract}
Background: Frontotemporal lobar degeneration (FTLD) can result in a decline in behavior, language, and motor function. Mealtime disturbances are a common and significant outcome of FTLD. Disturbances during mealtimes can arise from dysphagia or may occur secondary to behavioral changes such as rapid eating, mealtime rigidity, and altered diet preferences. Summary: Few studies have comprehensively evaluated eating behavior or dysphagia in individuals presenting with FTLD pathology despite the potential impact on medical safety and individual quality of life. Dysphagia is reported in the late stages of frontotemporal dementia and early in the motor subtypes of FTLD. The identification of dysphagia can alert individuals and medical teams to disease progression and provide insight into the nature and spread of the underlying neuropathology. Improved understanding of eating behaviors can improve individual care and may enhance diagnostic accuracy. Key Message: Aberrant eating behavior and swallowing difficulties are reported in the conditions associated with FTLD neuropathology. The consequences of mealtime disturbances include health risks associated with an increased BMI and aspiration, reduction of an individual's independence, and an increase in caregiver stress and burden. Here we review and summarize the literature on eating behavior and swallow impairments (dysphagia) in each of the syndromes caused by FTLD.
\end{abstract}


Lewis et al.: Review of Mealtime Difficulties following FTLD

\section{Introduction}

Frontotemporal lobar degeneration (FTLD) refers to the underlying pathological profile of a group of neurodegenerative disorders where progressive atrophy occurs in the frontal or temporal lobes of the brain. Consequences of FTLD include a decline in behavior, language, and motor function [1]. Mealtime disturbances are thought to be common sequelae of the neuropathology. Anecdotal reports describe individuals with insatiable appetite, altered food preferences, and dysphagia exhibited by coughing and choking throughout meals [2]. Dysphagia may lead to pneumonia, secondary to aspirated food and drink. Aspiration pneumonia is a common cause of death in disorders associated with FTLD [3-5]. Mealtime disturbances, a term used here to describe both behavioral and physical feeding impairments, are reported in all clinical syndromes associated with FTLD.

FTLD syndromes include behavioral-variant frontotemporal dementia (bvFTD), a disorder of behavior and cognition, and two language variants, primary progressive aphasia (PPA) and semantic dementia (SD). FTLD can also be associated with motor disturbance as observed in FTD with motor neuron disease (FTD-MND), corticobasal syndrome (CBS), and progressive supranuclear palsy (PSP) [6]. The heterogeneity of FTLD neuropathology results in each syndrome displaying a diverse and distinct profile of eating-related symptoms (Fig. 1). Disturbances during mealtimes can be characterized by physical difficulties eating, common in movement disorders, or by behavioral changes typically seen in the cognitive-behavioral presentations of FTLD.

An improved understanding of the pathology and symptomatology that contribute to mealtime disturbances following FTLD may lead to enhanced diagnostic accuracy, improved disease management, and a better understanding of the underlying neural mechanisms involved in the feeding process [7]. Few studies have evaluated eating behavior or dysphagia in individuals with FTLD neuropathology. Here we review and summarize the literature on eating behavior and swallowing impairments (dysphagia) in each of the syndromes caused by FTLD.

\section{Methods}

The databases PubMed, MEDLINE, and Embase were searched for the following keywords: "eating behavior" "dysphagia" "altered diet preference" "hyperphagia" "hyperoral" AND "frontotemporal dementia" "frontotemporal lobar degeneration" "behavioral variant frontotemporal dementia" "primary progressive aphasia" "semantic dementia" "progressive non-fluent aphasia" "corticobasal syndrome" "progressive supranuclear palsy." Books, gray literature, and reference lists of articles were also searched. All study types were included in the narrative review. Search terms were not required to be an outcome measure of the study. Articles were not excluded or evaluated for evidence quality due to the limited research from which to draw conclusions.

\section{Frontotemporal Lobar Degeneration}

Mealtime disturbances in FTLD are characterized by aberrant eating behaviors. Aberrant eating behaviors include continued eating despite reported satiety, eating rapidly, rigid eating behavior (e.g., only eating certain textures or at specific times), changes in diet preferences, food-seeking behavior, or obsessiveness regarding the next opportunity to eat [7-11].

FTLD-related feeding behaviors affect both the individual with FTD and the caregiver. The onset of disinhibition and impulsivity in FTD contribute to mealtime disturbances and lead to increased caregiver burden $[9,12-14]$. Mealtimes become a time of safety risks 


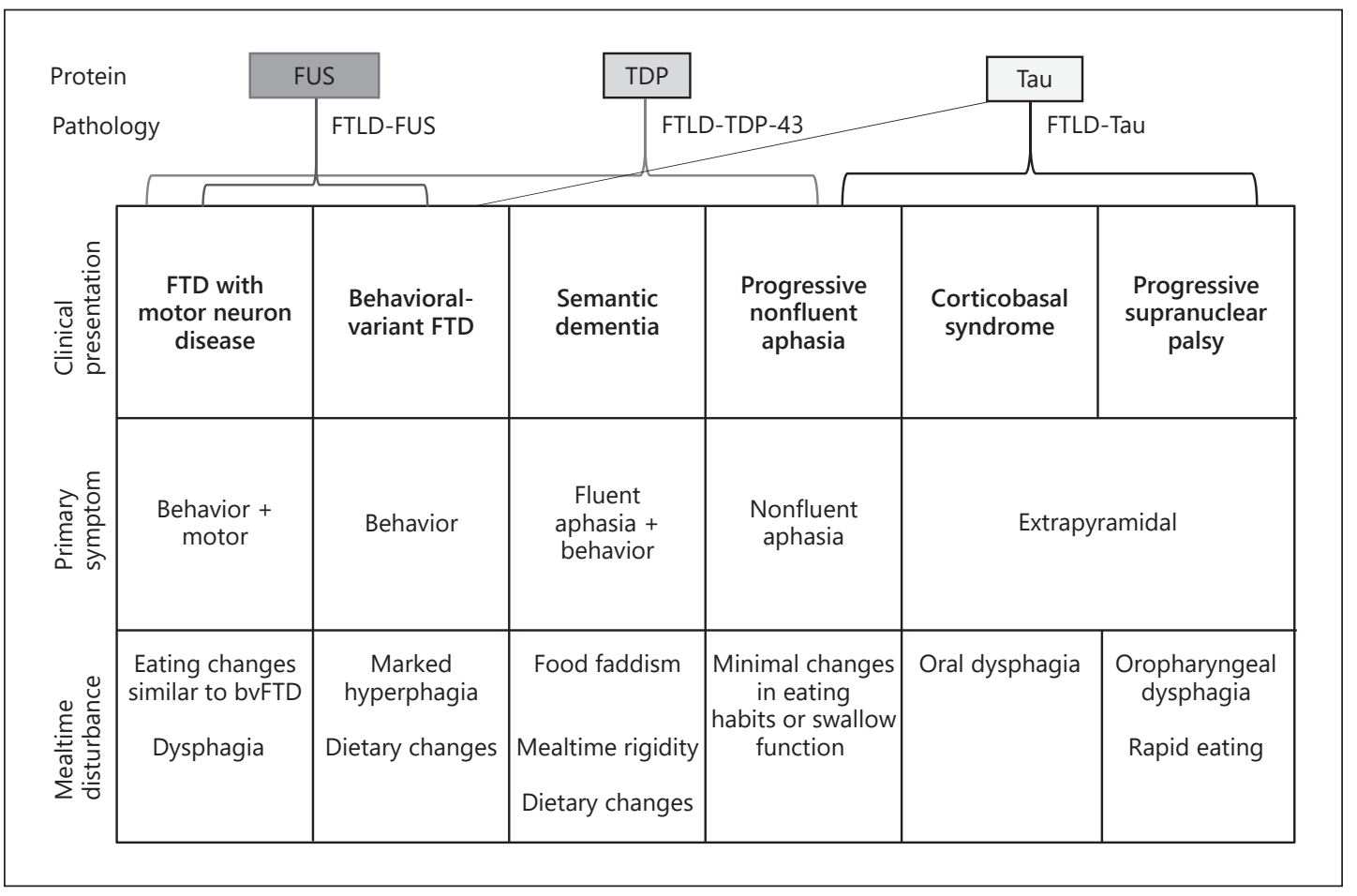

Fig. 1. Prominent mealtime difficulties in the clinical syndromes of FTLD. FTLD, frontotemporal lobar degeneration; FTD, frontotemporal dementia; bvFTD, behavioral-variant FTD.

requiring active supervision and monitoring by the caregiver [15-17]. The restriction of food by the caregiver can lead to tension between carer and individual, including aggression [17]. Health risks associated with aberrant eating behaviors include an increased BMI and the risk of aspiration $[4,10,17,18]$. Risky behaviors, such as rapidly eating large quantities of food, can induce aspiration and asphyxiation, even when swallow function is intact $[4,19,20]$. The nature and severity of symptoms leading to mealtime disturbances do not occur in the variants equally $[12,13,21,22]$.

\section{Behavioral-Variant Frontotemporal Dementia}

bvFTD is characterized by apathy, disinhibition, stereotypic/ritualistic behavior, loss of empathy, and altered eating behaviors [22-26]. Changes in diet and eating habits occur with a higher frequency and severity in bvFTD than in any other form of dementia [6, 8]. An estimated $60 \%$ of individuals with bvFTD present with altered eating behavior at the time of initial assessment. The rate increases to $80 \%$ over the progression of the disease [27]. Aberrant eating behavior is one of six key clinical features recognized under the consensus criteria for a diagnosis of bvFTD [6, 23-26]. Aberrant eating behavior is further specified in the diagnostic criteria as the symptoms of hyperphagia, dietary changes, and/or mouthing of inedible objects $[6,23]$.

\section{Hyperphagia}

Hyperphagia refers to the persistent and excessive desire to consume food [28-30] and is a component of several neurological syndromes and psychiatric conditions, such as PraderWilli and Kluver-Bucy syndrome, bulimia nervosa, and dementia [17, 29-31]. The compulsion to eat manifests as tachyphagia (eating rapidly) when food is present, or as aberrant food- 
seeking when food is not immediately available [28]. Food-seeking behaviors in bvFTD include stealing food from others, demanding food repetitively at inappropriate times, or leaving the immediate environment to seek out food [14, 28]. No significant difference in the prevalence of hyperphagia has been found between individuals with bvFTD characterized by disinhibition, and individuals with behaviors characterized by apathy, despite the disinhibited appearance of food-seeking and stealing [21].

There is no clear evidence that the sensation of hunger is a prompt for hyperphagic behaviors [7]. Appetite-regulating peptide levels in subjects with bvFTD are found to be consistent with an expected satiated state between meals [18, 32, 33]. Appetite-regulating peptide levels differ between subjects with bvFTD and healthy controls. Individuals with bvFTD have lower levels of ghrelin and cortisol and higher levels of insulin and agouti-related peptide than healthy controls. The changes in appetite-regulating peptide levels correspond to an increased BMI but not the onset of hyperphagia [32,33]. The relationship between appetite-regulating hormone level changes and FTLD neuropathology, and how these changes contribute to hyperphagia in bvFTD, is uncertain. One study suggested that peptide levels change to compensate for hyperphagia which occurs secondary to neural atrophy [32]. Alternatively, it has been suggested that changes in appetite-regulating peptide levels are a direct consequence of neural atrophy and contribute to the multifactorial nature of hyperphagia [18].

Atrophy of the right ventral insular cortex, striatum, rostral orbitofrontal cortex [34], and posterior hypothalamus [18, 35] has been associated with the onset and progression of hyperphagia. The hypothalamus is thought to be a key area involved in feeding behavior [7, $18,36,37]$. Atrophy of the hypothalamus, typically occurring within 2 years of a bvFTD diagnosis, is found to be specific to bvFTD and does not occur in PPA [18]. As hyperphagia occurs in all variants of FTLD, though most prominently and severely in bvFTD $[8,37]$, it is thought that hyperphagia is the result of multisystem disruption [18].

Hyperphagia can occur early during disease progression of bvFTD, making it a possible diagnostic indicator $[8,38]$. The high prevalence rate and severity of this feature may be valuable in distinguishing bvFTD from other FTLD subtypes and Alzheimer's dementia (AD) [7]. A recent study identified marked hyperphagia, as determined by total caloric intake, as being exclusive to the group with bvFTD [7]. The clinical attributes which may indicate the onset and progression rate of hyperphagia in bvFTD are undetermined [17,37,38]. The group at the greatest risk of displaying hyperphagic symptoms within a generalized dementia cohort are individuals with a younger age at disease onset and increased cognitive impairment [39].

Dietary Changes

Dietary changes co-occur with hyperphagia, as individuals with bvFTD have a tendency to repeatedly request or impulsively eat specific food types and flavors [31]. There does not appear to be a clear link between presymptomatic taste preferences and symptomatic preferences, as anecdotal reports describe individuals eating and requesting flavors previously disliked [40]. Changes in dietary preference are reported for all variants of FTLD [8, 10, 11, $34,41]$ and occur in other forms of dementia [11]. An increased preference for sweet-tasting foods and other carbohydrates is the most common dietary change and one of the earliest mealtime variances occurring in bvFTD $[8,10,34,41]$.

A specific preference for sweet-tasting foods, a "sweet tooth," can develop independently of, in addition to, and at a differing level of severity to a broader preference for carbohydrates $[10,41,42]$. The underlying biological mechanisms associated with the two preferences are thought to vary. A preference for sweet foods correlates with bilateral volume loss in the orbitofrontal cortices and unilateral, typically right, insula-striate area [7,34]. The preference for carbohydrates is associated with depleted levels of serotonin. The observation that carbo- 
hydrate cravings are reduced following the administration of selective serotonin reuptake inhibitors suggests that lowered serotonin levels may be a factor contributing to dietary changes in FTLD [42]. Serotonin levels are also found to be lower in individuals with AD and vascular dementia who have similar changes in dietary preferences [31].

Mouthing of Inedible Items

Mouthing of inedible objects is predominantly discussed as a component of hyperorality $[6,23-25]$; however, the rate of occurrence and severity of this symptom in bvFTD remain unclear $[8,21,23]$. The discrepancy in reported frequency may stem from inconsistent use of the term "hyperorality." Hyperorality in the bvFTD literature may refer to inappropriate oral exploration of objects [21], as the term is used in this review, or may be used in a more general context to describe any excessive oral behavior, such as hyperphagia, increased smoking, or substance abuse $[8,27,41]$.

Systematic studies assessing mouthing of inedible objects in bvFTD are scarce. Early citations regarding the occurrence of oral exploration in bvFTD reference single-subject case reports $[6,23,43]$. The limited studies that systematically examine hyperorality in bvFTD find the symptom to be relatively rare and predominately occur in the final stages of disease progression $[8,21]$. Mouthing of inedible objects is most likely when disinhibition is the primary behavioral symptom but not when apathy is the primary symptom of bvFTD [21]. The difference may provide insight into the region of atrophy. Disinhibition in bvFTD is associated with atrophy of the temporal poles, whereas apathy is associated with frontal lobe atrophy $[21,44]$, which suggests that mouthing of inedible objects may be related to temporal lobe atrophy.

\section{Primary Progressive Aphasia}

PPA is divided into three variants: SD, progressive nonfluent aphasia (PNFA), and logopenic-variant PPA [24, 26, 45-48]. All variants of PPA may be associated with AD, FTLD-tau, and FTLD-TDP pathology $[47,48]$. Only SD and PNFA are subsumed under FTLD. Logopenicvariant PPA is associated with a comparatively higher rate of AD pathology and is therefore recognized as a language-onset variant of $\mathrm{AD}[47,49]$. Behavior and motor impairments are not prominent or early features of PPA, and perhaps for this reason the literature regarding feeding and swallowing difficulties in PPA remains limited. The available evidence demonstrates that aberrant eating behavior and dysphagia are present in individuals with PPA. Its onset typically occurs in the late stages of the disease [4, 8, 21, 50-54].

Semantic Dementia

SD is associated with the progressive loss of concepts and meanings $[6,21,55]$. The loss of conceptual knowledge characteristic of SD contributes to behavioral changes and serves as a feature distinguishing between feeding impairments in SD and the other clinical syndromes of FTLD.

Aberrant eating behavior in SD resembles a milder form of the bvFTD feeding symptomatology $[4,8,10]$, but differences have been identified and have potential diagnostic importance [8]. These differences include a greater preference for sweets as with bvFTD or AD [8, 10,18 ], food faddism (i.e., will only consume certain flavors, textures, or colors) [8], and rigid, ritualistic mealtime behaviors (i.e., will only eat at certain times or locations) [12, 21, 56]. Neural correlates of food faddism and rigid eating behavior have not been addressed in brain imaging studies. It is speculated that the behaviors are secondary to the progressing impairment of semantic knowledge $[21,57,58]$, i.e., limited semantic knowledge inhibits the recognition of alternative options. For example, in the presence of intact stimulus discrimination and after controlling for the degree of language impairment, SD subjects were found 
to have marked difficulty in correctly associating sensory stimuli, such as smell and taste, with the corresponding food items [57-59]. Hyperorality is found to occur most frequently in SD as compared to other syndromes associated with FTLD or AD [8]. The inability to integrate information secondary to poor multimodal semantic knowledge may contribute to hyperorality. This is attributed to an associative agnosia regarding the edibility of items and an understanding of the conditions in which items can be eaten (i.e., foods eaten raw vs. cooked, peeled, etc. $[4,8,52,58]$.

Aberrant eating behavior in SD is found to positively correlate with declining cognitivebehavioral function [57] and displays a predictable pattern of symptom onset $[8,60]$. Findings suggest that changes in food preferences (e.g., increased sugar intake, requesting specific food items, etc.) occur very early in disease progression, followed by a concurrent increase in appetite and altered eating habits (i.e., rigid or ritualistic behaviors) [8], with oral exploration of inedible objects and dysphagia, if present at all, occurring in the final stages $[4,8,21,52]$.

Progressive Nonfluent Aphasia

PNFA is the least common of the FTLD variants [45]. Symptoms include apraxia of speech and agrammatism, with behavioral and cognitive function remaining relatively unimpaired [45]. Changes in eating behavior occur less severely and with a later onset than in SD or bvFTD $[6,53]$.

Monitoring of eating habits and dysphagia remains important in PNFA, given the potential phenotypic overlap with PSP and CBS [61-63]. Previous work has shown that the FTLD motor phenotypes can present with symptoms that meet the criteria for a diagnosis of PNFA [64, 65]. A study from 2006 found that $70 \%$ of individuals diagnosed with PNFA had either CBS or PSP pathology when examined at autopsy [66]. Clinical screening for swallow impairments and aberrant eating behaviors, combined with an instrumental swallow assessment as indicated, shows good potential as a method for improving the diagnostic distinction between PNFA and motor disorders [4, 67]. A better understanding of changes in eating behavior and swallow function following FTLD is first needed to establish a platform on which diagnostic screening tools can be developed.

\section{Swallow Function in FTD}

Dysphagia, concomitant with motor speech deficits, is one of the initial signs of bulbar onset in FTLD $[4,68]$. Pulmonary aspiration is a common and serious consequence of dysphagia. If sensation is intact, aspiration immediately induces reflexive coughing and tachypnea, which can be distressing for the individual and caregivers. The individual is at a high risk of developing a fatal aspiration pneumonia if aspiration is recurrent, sensation is poor, or the immune system is weakened [4].

Dysphagia in FTD is often first observed and chiefly characterized by delayed swallow initiation during mealtime assessments [52]. The swallow is further characterized by premature spillage of the bolus into the pharynx during mastication and reduced movement of the bolus through the pharynx when instrumental investigation is utilized [4]. Mild dysphagia has been found to occur in $57 \%$ of FTLD participants, with minimal variance across group subtypes as assessed by fiberoptic endoscopic examination of swallowing [4]. Moderateto-severe dysphagia typically occurs only in the final stages of FTLD and is clinically observed as delayed swallow initiation $[4,8]$.

The occurrence and severity of dysphagia in the presentation of FTLD is thought to be one of the most accurate predictors of shorter survival, especially when the onset occurs prior to behavioral symptoms $[13,51]$. Dysphagia which presents early in disease progression is attributed to a rapidly progressing neuropathology and is commonly a prodrome of FTD-MND $[4,51]$. 
Lewis et al.: Review of Mealtime Difficulties following FTLD

\section{Motor Disorders with FTLD Neuropathology}

FTD-MND, CBS, and PSP are common motor syndromes associated with FTLD-type presentations. Mealtime disturbances in these disorders are secondary to physical deficits such as oropharyngeal weakness, oral apraxia, reduced sensation, decreased breath support, and/or poor feeding posture $[5,19,20]$.

Dysphagia is the most common reason for admission to palliative care units for individuals with PSP and CBS. It is also associated with poor treatment outcomes during palliative care and is linked to a higher risk of dying from respiration-related causes compared to individuals with Parkinson's disease [5, 69]. Alterations in eating behavior, except in FTD-MND, do not frequently occur until the late stages of disease progression $[19,20,68]$.

\section{Frontotemporal Dementia with Motor Neuron Disease}

MND occurs in $10-15 \%$ of individuals initially diagnosed with bvFTD $[25,70]$, with a further 25-30\% of individuals displaying motor symptoms insufficient to reach MND criteria [70]. FTD-MND is more insidious than either MND or bvFTD individually and has the shortest survival expectancy of any of the FTLD phenotypes [54]. Individuals with FTD-MND are at an increased risk of displaying feeding behaviors characteristic of bvFTD in combination with a deteriorating swallow function [4, 54]. Oropharyngeal weakness, progressive hyperphagia, and expiratory muscle weakness puts the FTD-MND population at a high risk of aspirating food and drink [51]. Respiratory failure secondary to aspiration pneumonia is a leading cause of death in FTD-MND [22].

\section{Corticobasal Syndrome}

Mealtime difficulties in CBS present late [71] and are characterized by impairment of the voluntary phase of swallowing [72]. The onset of progressive apraxia of speech is found to be the best indicator of possible dysphagia in CBS [19]. Progressive apraxia of speech presents as uncoordinated oral motor movements and is a prominent symptom in CBS [20, 72-75]. Individuals with CBS often present with reduced bolus control and require multiple swallows to clear the oral cavity, referred to as piecemeal deglutition $[19,72]$. Individuals with CBS are thought to lack awareness of their dysphagia, as self-report has shown poor validity when further assessed by videofluoroscopic swallowing study (VFSS) [19].

Dementia with frontal-lobe-type behavioral changes can occur in CBS, but to date, changes in eating behavior have not been reported with any frequency in this population $[71,76,77]$. Cognitive functioning is not found to correlate with swallow impairment, either by self-report or VFSS [19].

\section{Progressive Supranuclear Palsy}

PSP is characterized by both oral and pharyngeal swallowing deficits occurring early in disease onset [78-80]. Dysphagia, often secondary to bradykinesia, is characterized by oral weakness, delayed swallow initiation, and reduced laryngeal elevation [20, 79, 81]. Levodopa, commonly prescribed to treat dysphagia in individuals with Parkinson's disease, is ineffective in treating the bradykinesia-related swallow impairments of PSP [79, 81, 82]. Postural modification in combination with modified diet texture presents the best current treatment option for managing dysphagia $[79,83]$.

Individuals with PSP are thought to present an accurate awareness of their difficulty eating and drinking when assessed by questionnaire and verified by VFSS $[78,79]$. The degree of cognitive impairment positively correlates to both individual reports of difficulty and clinician-observed swallow impairment $[20,83]$. Aberrant eating behaviors - namely, impulsive eating - are reported in PSP $[79,81,84]$. 
Table 1. Pharmaceutical treatment

\begin{tabular}{|c|c|c|c|c|c|}
\hline Study [Ref.], year & Study type & Demographics & Drug class & Drug name & Results \\
\hline $\begin{array}{l}\text { Pompanin et al. } \\
\text { [93], } 2014\end{array}$ & Case report & $\begin{array}{l}\text { 64-YO female } \\
\text { bvFTD } \\
\text { MMSE } 24 / 30\end{array}$ & $\begin{array}{l}\text { SSRI } \\
\text { Antiepileptic }\end{array}$ & $\begin{array}{l}\text { Fluvoxamine }(100 \mathrm{mg} / \text { day }) \\
\text { with topiramate } \\
(50 \mathrm{mg} / \text { day })\end{array}$ & $\begin{array}{l}\text { Improvement in binge-eating as } \\
\text { evidenced by } 5-\mathrm{kg} \text { weight loss in a } \\
\text { month }\end{array}$ \\
\hline $\begin{array}{l}\text { Shinagawa et al. } \\
{[94], 2013}\end{array}$ & Case reports & $\begin{array}{l}\text { Case 1: } 78 \text {-YO female } \\
\text { bvFTD; MMSE } 16 / 30 \\
\text { Case 2: } 47-Y 0 \text { male } \\
\text { SD; MMSE } 10 / 30 \\
\text { Case 3: } 57-Y 0 \text { male } \\
\text { FTLD (no lobar atrophy) } \\
\text { MMSE } 20 / 30\end{array}$ & Antiepileptic & $\begin{array}{l}\text { Topiramate } \\
\text { (Cases } 1+2: 100 \mathrm{mg} / \text { day; } \\
\text { Case } 3: 150 \mathrm{mg} / \text { day) }\end{array}$ & $\begin{array}{l}\text { Cases } 1+2 \text { : improvement only in } \\
\text { compulsive eating behaviors as } \\
\text { evidenced by APEHQ score } \\
\text { Case } 3 \text { : no significant changes in } \\
\text { eating behavior }\end{array}$ \\
\hline $\begin{array}{l}\text { Singam et al. [95], } \\
2013\end{array}$ & Case report & $\begin{array}{l}41-Y 0 \text { male } \\
\text { bvFTD }\end{array}$ & Antiepileptic & Topiramate & $\begin{array}{l}\text { Improvements in hyperphagia and } \\
\text { seeking out of sweets after } 3 \text { weeks }\end{array}$ \\
\hline Nestor [96], 2012 & Case report & $\begin{array}{l}56-Y O \text { male } \\
\text { FTLD with rostral } \\
\text { temporal lobe atrophy }\end{array}$ & $\begin{array}{l}\text { SSRI } \\
\text { Antiepileptic } \\
\text { Antipsychotic }\end{array}$ & $\begin{array}{l}\text { Fluvoxamine ( } 150 \mathrm{mg} / \text { day }) \\
\text { Topiramate }(25 \mathrm{mg} / \text { day }) \\
\text { Olanzapine }(5 \mathrm{mg} / \text { day })\end{array}$ & $\begin{array}{l}\text { Weight loss, normal eating rate, and } \\
\text { reduction in sweet food and alcohol } \\
\text { intake reported by spouse }\end{array}$ \\
\hline $\begin{array}{l}\text { Cruz et al. [97], } \\
2008\end{array}$ & Case report & $\begin{array}{l}\text { 53-YO male } \\
\text { FTD; MMSE 16/30 }\end{array}$ & Antiepileptic & $\begin{array}{l}\text { Topiramate (initiated } \\
100 \mathrm{mg} / \text { day, further } \\
\text { increased to } 100 \mathrm{mg} / \text { b.i.d.) }\end{array}$ & $\begin{array}{l}\text { Improvement in alcohol abuse, per } \\
\text { spouse report; no improvement in } \\
\text { compulsive eating of sweet and } \\
\text { carbohydrate food groups }\end{array}$ \\
\hline $\begin{array}{l}\text { Lebert et al. [98], } \\
2004\end{array}$ & $\begin{array}{l}\text { Randomized } \\
\text { placebo- } \\
\text { controlled trial }\end{array}$ & $\begin{array}{l}16 \text { females, } 15 \text { males } \\
\text { Mean age } 61.7 \text { years } \\
\text { FTD } \\
\text { MMSE } 20.8 \pm 8.3\end{array}$ & $\begin{array}{l}\text { Antidepressant } \\
\text { (atypical } \\
\text { serotonergic agent) }\end{array}$ & Trazodone & $\begin{array}{l}\text { Participants with more severe } \\
\text { aberrant behaviors, per NPI, } \\
\text { demonstrated the greatest response } \\
\text { to treatment }\end{array}$ \\
\hline $\begin{array}{l}\text { Moretti et al. [99], } \\
2003\end{array}$ & $\begin{array}{l}\text { Randomized, } \\
\text { controlled, } \\
\text { open-label trial }\end{array}$ & $\begin{array}{l}\text { Group A: } \\
3 \text { males, } 5 \text { females } \\
\text { Age } 64.56 \pm 4.46 \text { years } \\
\text { FTD (bvFTD and SD) } \\
\text { MMSE } 24.125 \pm 1.88 \\
\text { Group B: } \\
3 \text { males, } 5 \text { females } \\
\text { Age } 64.56 \pm 3.21 \text { years } \\
\text { FTD (bvFTD and SD) } \\
\text { MMSE } 22.875 \pm 2.99\end{array}$ & $\begin{array}{l}\text { Group A: SSRI } \\
\text { Group B: nootropic }\end{array}$ & $\begin{array}{l}\text { Paroxetine }(20 \mathrm{mg} / \text { day }) \\
\text { Piracetam }(1,200 \mathrm{mg} / \text { day })\end{array}$ & $\begin{array}{l}\text { Group A showed statistically } \\
\text { significant improvements in } \\
\text { behavioral symptoms; an } \\
\text { improvement in eating behavior } \\
\text { could be demonstrated with } \\
\text { long-term use }\end{array}$ \\
\hline $\begin{array}{l}\text { Swartz et al. [42], } \\
1997\end{array}$ & $\begin{array}{l}\text { Prospective } \\
\text { clinical trial }\end{array}$ & $\begin{array}{l}7 \text { males, } 4 \text { females } \\
\text { Mean age } 60.4 \text { years } \\
\text { FTD } \\
\text { MMSE } 22.9 \pm 5.1\end{array}$ & SSRI & $\begin{array}{l}\text { Fluoxetine ( } 20 \mathrm{mg} / \text { day) } \\
(n=5) \\
\text { Sertraline (range } 50-125 / \\
\text { day) }(n=5) \\
\text { Paroxetine }(20 \mathrm{mg} / \text { day) } \\
(n=1)\end{array}$ & $\begin{array}{l}\text { Carbohydrate cravings improved in } \\
56 \% \text { of participants }\end{array}$ \\
\hline
\end{tabular}

APEHQ, Appetite and Eating Habits Questionnaire; bvFTD, behavioral-variant frontotemporal dementia; FTD, frontotemporal dementia; FTLD, frontotemporal lobar degeneration; MMSE, Mini-Mental State Examination; NPI, Neuropsychiatric Inventory; SD, semantic dementia; SSRI, selective serotonin reuptake inhibitor; YO, year-old.

\section{Treatment}

Current treatments for aberrant eating behavior in FTLD are intended to ameliorate symptoms rather than modify the disease [85]. Mealtime disturbances are primarily managed by increased caregiver supervision. Recommended management techniques include locking food away, reducing access to large portions, monitoring for food-seeking or stealing, providing healthy alternatives to sweets, cueing the individual to slow down during meals, modifying diet texture as needed, and ensuring proper body positioning for safe swallowing (e.g., bolt upright) $[16,79,85,86]$. Rehabilitation clinicians can assist caregivers in modifying the eating environment, providing appropriate cues during meals, managing dietary changes, and reducing aspiration risks [87]. Speech pathologists can provide alternative communication methods for individuals unable to verbalize wants and needs during mealtime. To 
date, there have been no clinical trials on managing mealtime difficulties following FTLD [88]. Studies of behavioral and environmental interventions in FTD, including behaviors not related to mealtime, are restricted to case reports [16].

The literature regarding pharmaceutical interventions for aberrant eating behaviors (described in Table 1) is primarily limited to case reports. Topiramate, an antiepileptic drug with a side effect of appetite suppression, has been reported to reduce hyperphagia. The antidepressant class of selective serotonin reuptake inhibitors have some benefit for altered dietary preferences [85]. Pharmaceutical management also includes identifying prescribed medications which may be exacerbating eating behavioral symptoms [89].

\section{Limitations of the Literature}

\section{Caregiver Report}

A description of assessment measures was not included in this review, as it has recently been discussed $[37,90,91]$. Caregiver report has been the predominant method used to assess dietary changes and eating behaviors throughout the literature. Caregiver questionnaires are limited by subjectivity and are susceptible to the caregiver's quality of life. Caregivers with a higher sense of perceived burden, affected by secondary factors such as poor environmental support, are more likely to rate the individual they care for as having an increased severity and frequency of symptoms [92]. Caregivers of individuals with FTD report a higher rate of stress than caregivers of other types of dementia. Biases associated with caregiver burden need to be considered when examining the presence and severity of mealtime disturbances in FTD by caregiver rating or description of symptoms. A study comparing caregivers' report of symptoms of hyperphagia to clinician observation illustrates this effect. The study found that caregivers trended towards overrating the presence and severity of symptoms. Thirty percent of the subjects identified as having hyperphagia based on caregiver report of symptoms did not meet the criterion for classification when the term "hyperphagia" was standardized to mean consumption which is greater than 2 standard deviations from the norm [17].

\section{Limited Studies and Population Sizes}

Research regarding mealtime difficulties following FTLD is limited by the number of studies that systematically examine eating behavior or dysphagia exclusively. Much of the evidence on mealtime difficulties in FTD is derived from the Cambridge Behavioral Inventory (CBI). The CBI is designed to discriminate between FTD and AD [12]. Studies using the CBI report differences in eating behavior between FTD and AD; however, change in eating behavior is one of many cognitive-behavioral symptoms described. The aim of these studies is typically to capture a broad spectrum of behaviors, and therefore they do not provide an in-depth description of the eating behaviors or their progression [35]. There is a paucity of research which evaluates swallowing impairment following FTLD, as only a few studies use instrumental investigation to fully describe the impairments $[4,8,19,20,52,79]$.

The quality of the included studies was not formally assessed for this review. Many of the randomized controlled trials which evaluate changes in eating behavior and swallow function following FTLD are based on relatively small cohorts. Other studies describe anecdotal evidence or are case reports. 
Lewis et al.: Review of Mealtime Difficulties following FTLD

\section{Conclusions and Future Direction}

Cognitive and motor impairments can have devastating effects on activities of daily living. Mealtime is especially susceptible to these deficits. Aberrant eating behavior and swallowing difficulties can drastically reduce an individual's independence and greatly increase caregiver stress. Current standardized assessments designed to evaluate mealtime disturbances in the FTLD population are limited as they draw on third-party reporting or are limited in number and population size. The identification of features, such as mealtime disturbances, which hasten a diagnosis is a key area of exploration within the field neurodegeneration research. It is not until mealtime disturbances have been adequately characterized that researchers can begin to develop interventions to extend feeding independence and improve the quality of life of individuals with syndromes resulting from FTLD.

\section{Disclosure Statement}

C.L. is funded by an Australian Postgraduate Award. M.W. and D.V. report no relevant disclosures. A.P.V. is funded by a National Health and Medical Research Council, Australia Dementia Fellowship (\#1135683). A.P.V. is Chief Science Officer of Redenlab.

\section{Author Contributions}

C.L.: acquisition of data, analysis or interpretation of data, and drafting of the manuscript. M.W.: analysis or interpretation of data and critical revision of the manuscript for intellectual content. D.V.: analysis or interpretation of data and critical revision of the manuscript for intellectual content. A.P.V.: study concept and design, interpretation of findings, revision of the manuscript, and study supervision.

\section{References}

1 Rabinovici GD, Miller BL. Frontotemporal lobar degeneration: epidemiology, pathophysiology, diagnosis and management. CNS Drugs. 2010 May;24(5):375-98.

2 Hall GR, Shapira J, Gallagher M, Denny SS. Managing differences: care of the person with frontotemporal degeneration. J Gerontol Nurs. 2013 Mar;39(3):10-4.

3 Mendez MF, Cummings JL. Dementia: A clinical approach. Philadelphia: Butterworth-Heinemann; 2003.

4 Langmore SE, Olney RK, Lomen-Hoerth C, Miller BL. Dysphagia in patients with frontotemporal lobar dementia. Arch Neurol. 2007 Jan;64(1):58-62.

5 Bükki J, Nübling G, Lorenzl S. Managing advanced progressive supranuclear palsy and corticobasal degeneration in a palliative care unit: admission triggers and outcomes. Am J Hosp Palliat Care. 2016 Jun;33(5):47782.

6 Neary D, Snowden JS, Gustafson L, Passant U, Stuss D, Black S, et al. Frontotemporal lobar degeneration: a consensus on clinical diagnostic criteria. Neurology. 1998 Dec;51(6):1546-54.

7 Ahmed RM, Irish M, Henning E, Dermody N, Bartley L, Kiernan MC, et al. Assessment of Eating Behavior Disturbance and Associated Neural Networks in Frontotemporal Dementia. JAMA Neurol. 2016 Mar; 73(3):282-90.

8 Ikeda M, Brown J, Holland AJ, Fukuhara R, Hodges JR. Changes in appetite, food preference, and eating habits in frontotemporal dementia and Alzheimer's disease. J Neurol Neurosurg Psychiatry. 2002 Oct;73(4):371-6.

9 Kumamoto K, Arai Y, Hashimoto N, Ikeda M, Mizuno Y, Washio M. Problems family caregivers encounter in home care of patients with frontotemporal lobar degeneration. Psychogeriatrics. 2004;4(2):33-9.

10 Ahmed RM, Irish M, Kam J, van Keizerswaard J, Bartley L, Samaras K, et al. Quantifying the eating abnormalities in frontotemporal dementia. JAMA Neurol. 2014 Dec;71(12):1540-6.

11 Morris CH, Hope RA, Fairburn CG. Eating habits in dementia. A descriptive study. Br J Psychiatry. 1989 Jun; 154(06):801-6.

12 Bozeat S, Gregory CA, Ralph MA, Hodges JR. Which neuropsychiatric and behavioural features distinguish frontal and temporal variants of frontotemporal dementia from Alzheimer's disease? J Neurol Neurosurg Psychiatry. 2000 Aug;69(2):178-86.

13 Liu W, Miller BL, Kramer JH, Rankin K, Wyss-Coray C, Gearhart R, et al. Behavioral disorders in the frontal and temporal variants of frontotemporal dementia. Neurology. 2004 Mar;62(5):742-8. 
Lewis et al.: Review of Mealtime Difficulties following FTLD

14 Mendez MF, Licht EA, Shapira JS. Changes in dietary or eating behavior in frontotemporal dementia versus Alzheimer's disease. Am J Alzheimers Dis Other Demen. 2008 Jun-Jul;23(3):280-5.

15 Mendez MF. Frontotemporal dementia: therapeutic interventions. Front Neurol Neurosci. 2009;24:168-78.

16 Manoochehri M, Huey ED. Diagnosis and management of behavioral issues in frontotemporal dementia. Curr Neurol Neurosci Rep. 2012 Oct;12(5):528-36.

17 Keene JM, Hope T. Hyperphagia in dementia: 1. The use of an objective and reliable method for measuring hyperphagia in people with dementia. Appetite. 1997 Apr;28(2):151-65.

18 Ahmed RM, Latheef S, Bartley L, Irish M, Halliday GM, Kiernan MC, et al. Eating behavior in frontotemporal dementia: peripheral hormones vs hypothalamic pathology. Neurology. 2015 Oct;85(15):1310-7.

19 Grunho M, Sonies B, Frattali CM, Litvan I. Swallowing disturbances in the corticobasal syndrome. Parkinsonism Relat Disord. 2015 Nov;21(11):1342-8.

20 Litvan I, Sastry N, Sonies BC. Characterizing swallowing abnormalities in progressive supranuclear palsy. Neurology. 1997 Jun;48(6):1654-62.

21 Snowden JS, Bathgate D, Varma A, Blackshaw A, Gibbons ZC, Neary D. Distinct behavioural profiles in frontotemporal dementia and semantic dementia. J Neurol Neurosurg Psychiatry. 2001 Mar;70(3):323-32.

22 Neary D, Snowden JS, Mann DM. Classification and description of frontotemporal dementias. Ann N Y Acad Sci. 2000;920(1):46-51.

23 Rascovsky K, Hodges JR, Knopman D, Mendez MF, Kramer JH, Neuhaus J, et al. Sensitivity of revised diagnostic criteria for the behavioural variant of frontotemporal dementia. Brain. 2011 Sep;134(Pt 9):2456-77.

24 Chare L, Hodges JR, Leyton CE, McGinley C, Tan RH, Kril JJ, et al. New criteria for frontotemporal dementia syndromes: clinical and pathological diagnostic implications. J Neurol Neurosurg Psychiatry. 2014 Aug;85(8): 865-70.

25 Piguet 0, Hornberger M, Mioshi E, Hodges JR. Behavioural-variant frontotemporal dementia: diagnosis, clinical staging, and management. Lancet Neurol. 2011 Feb;10(2):162-72.

26 Rascovsky K, Grossman M. Clinical diagnostic criteria and classification controversies in frontotemporal lobar degeneration. Int Rev Psychiatry. 2013 Apr;25(2):145-58.

27 Piguet O, Hornberger M, Shelley BP, Kipps CM, Hodges JR. Sensitivity of current criteria for the diagnosis of behavioral variant frontotemporal dementia. Neurology. 2009 Feb;72(8):732-7.

28 Skuse D, Albanese A, Stanhope R, Gilmour J, Voss L. A new stress-related syndrome of growth failure and hyperphagia in children, associated with reversibility of growth-hormone insufficiency. Lancet. 1996 Aug; 348(9024):353-8.

29 McElroy S, Kotwal R. Binge eating. In: Hollander E, Stein D, editors. Clinical manual of impulse-control disorders. Arlington (VA): American Psychiatric Publishing; 2006. p. 115-48.

30 Holm VA, Cassidy SB, Butler MG, Hanchett JM, Greenswag LR, Whitman BY, et al. Prader-Willi syndrome: consensus diagnostic criteria. Pediatrics. 1993 Feb;91(2):398-402.

31 Keene JM, Hope T. Hyperphagia in dementia: 2. Food choices and their macronutrient contents in hyperphagia, dementia and ageing. Appetite. 1997 Apr;28(2):167-75.

32 Woolley JD, Khan BK, Natesan A, Karydas A, Dallman M, Havel P, et al. Satiety-related hormonal dysregulation in behavioral variant frontotemporal dementia. Neurology. 2014 Feb;82(6):512-20.

33 Alberici A, Bocchio L, Geroldi C, Zanardini R, Bonomini C, Bugari G, et al. Serum leptin levels are higher in females affected by frontotemporal lobar degeneration than Alzheimer's disease. J Neurol Neurosurg Psychiatry. 2008 Jun; 79(6):712-5.

34 Woolley JD, Gorno-Tempini ML, Seeley WW, Rankin K, Lee SS, Matthews BR, et al. Binge eating is associated with right orbitofrontal-insular-striatal atrophy in frontotemporal dementia. Neurology. 2007 Oct;69(14): 1424-33.

35 Piguet 0. Eating disturbance in behavioural-variant frontotemporal dementia. J Mol Neurosci. 2011 Nov; 45(3):589-93.

36 Dietrich MO, Zimmer MR, Bober J, Horvath TL. Hypothalamic Agrp neurons drive stereotypic behaviors beyond feeding. Cell. 2015 Mar;160(6):1222-32.

37 Piguet O, Petersén A, Yin Ka Lam B, Gabery S, Murphy K, Hodges JR, et al. Eating and hypothalamus changes in behavioral-variant frontotemporal dementia. Ann Neurol. 2011 Feb;69(2):312-9.

38 Diehl-Schmid J, Pohl C, Perneczky R, Förstl H, Kurz A. Behavioral disturbances in the course of frontotemporal dementia. Dement Geriatr Cogn Disord. 2006;22(4):352-7.

39 Smith G, Vigen V, Evans J, Fleming K, Bohac D. Patterns and associates of hyperphagia in patients with dementia. Neuropsychiatry Neuropsychol Behav Neurol. 1998 Apr;11(2):97-102.

40 Lipton AM, Boxer A. Frontotemporal Dementia. In: Weiner MF, Lipton AM, editors. The American Psychiatric Publishing textbook of Alzheimer disease and other dementias. Washington (DC): American Psychiatric Publishing; 2009. p. 219-27.

41 Miller BL, Darby AL, Swartz JR, Yener GG, Mena I. Dietary changes, compulsions and sexual behavior in frontotemporal degeneration. Dementia. 1995 Jul-Aug;6(4):195-9.

42 Swartz JR, Miller BL, Lesser IM, Darby AL. Frontotemporal dementia: treatment response to serotonin selective reuptake inhibitors. J Clin Psychiatry. 1997 May;58(5):212-6.

43 Mendez MF, Foti DJ. Lethal hyperoral behaviour from the Klüver-Bucy syndrome. J Neurol Neurosurg Psychiatry. 1997 Mar;62(3):293-4. 
44 Lilly R, Cummings JL, Benson DF, Frankel M. The human Klüver-Bucy syndrome. Neurology. 1983 Sep;33(9): 1141-5.

45 Gorno-Tempini ML, Hillis AE, Weintraub S, Kertesz A, Mendez M, Cappa SF, et al. Classification of primary progressive aphasia and its variants. Neurology. 2011 Mar;76(11):1006-14.

46 Mesulam MM, Weintraub S. Is it time to revisit the classification guidelines for primary progressive aphasia? Neurology. 2014 Apr;82(13):1108-9.

47 Vandenberghe R. Classification of the primary progressive aphasias: principles and review of progress since 2011. Alzheimers Res Ther. 2016 Apr;8(1):16.

48 Bonner MF, Ash S, Grossman M. The new classification of primary progressive aphasia into semantic, logopenic, or nonfluent/agrammatic variants. Curr Neurol Neurosci Rep. 2010 Nov;10(6):484-90.

49 Mesulam MM, Weintraub S, Rogalski EJ, Wieneke C, Geula C, Bigio EH. Asymmetry and heterogeneity of Alzheimer's and frontotemporal pathology in primary progressive aphasia. Brain. 2014 Apr;137(Pt 4):117692.

50 Fuh JL, Liao KK, Wang SJ, Lin KN. Swallowing difficulty in primary progressive aphasia: a case report. Cortex. 1994 Dec;30(4):701-5.

51 Gräsbeck A, Englund E, Horstmann V, Passant U, Gustafson L. Predictors of mortality in frontotemporal dementia: a retrospective study of the prognostic influence of pre-diagnostic features. Int J Geriatr Psychiatry. 2003 Jul;18(7):594-601.

52 Marin Sde M, Bertolucci PH, Marin LF, de Oliveira FF, Wajman JR, Bahia VS, et al. Swallowing in primary progressive aphasia. NeuroRehabilitation. 2016;38(1):85-92.

53 Rosen HJ, Allison SC, Ogar JM, Amici S, Rose K, Dronkers N, et al. Behavioral features in semantic dementia vs other forms of progressive aphasias. Neurology. 2006 Nov;67(10):1752-6.

54 Hodges JR, Davies R, Xuereb J, Kril J, Halliday G. Survival in frontotemporal dementia. Neurology. 2003 Aug; 61(3):349-54.

55 Snowden JS, Goulding PJ, Neary D. Semantic dementia: a form of circumscribed cerebral atrophy. Behav Neurol. 1989;2(3):167-82.

56 Thompson AE, Clark CN, Hardy CJ, Fletcher PD, Greene J, Rohrer JD, et al. Two cases of food aversion with semantic dementia. Neurocase. 2016 Jun;22(3):312-6.

57 Piwnica-Worms KE, Omar R, Hailstone JC, Warren JD. Flavour processing in semantic dementia. Cortex. 2010 Jun;46(6):761-8.

58 Omar R, Mahoney CJ, Buckley AH, Warren JD. Flavour identification in frontotemporal lobar degeneration. J Neurol Neurosurg Psychiatry. 2013 Jan;84(1):88-93.

59 Pardini M, Huey ED, Cavanagh AL, Grafman J. Olfactory function in corticobasal syndrome and frontotemporal dementia. Arch Neurol. 2009 Jan;66(1):92-6.

60 Shinagawa S, Ikeda M, Nestor PJ, Shigenobu K, Fukuhara R, Nomura M, et al. Characteristics of abnormal eating behaviours in frontotemporal lobar degeneration: a cross-cultural survey. J Neurol Neurosurg Psychiatry. 2009 Dec;80(12):1413-4.

61 Sha S, Hou C, Viskontas IV, Miller BL. Are frontotemporal lobar degeneration, progressive supranuclear palsy and corticobasal degeneration distinct diseases? Nat Clin Pract Neurol. 2006 Dec;2(12):658-65.

62 Santos-Santos MA, Mandelli ML, Binney RJ, Ogar J, Wilson SM, Henry ML, et al. Features of patients with nonfluent/agrammatic primary progressive aphasia with underlying progressive supranuclear palsy pathology or corticobasal degeneration. JAMA Neurol. 2016 Jun;73(6):733-42.

63 Espay AJ, Litvan I. Parkinsonism and frontotemporal dementia: the clinical overlap. J Mol Neurosci. 2011 Nov; 45(3):343-9.

64 Williams DR, Lees AJ. Progressive supranuclear palsy: clinicopathological concepts and diagnostic challenges. Lancet Neurol. 2009 Mar;8(3):270-9.

65 Rohrer JD, Guerreiro R, Vandrovcova J, Uphill J, Reiman D, Beck J, et al. The heritability and genetics of frontotemporal lobar degeneration. Neurology. 2009 Nov;73(18):1451-6.

66 Josephs KA, Petersen RC, Knopman DS, Boeve BF, Whitwell JL, Duffy JR, et al. Clinicopathologic analysis of frontotemporal and corticobasal degenerations and PSP. Neurology. 2006 Jan;66(1):41-8.

67 Vogel AP, Rommel N, Sauer C, Horger M, Krumm P, Himmelbach M, et al. Clinical assessment of dysphagia in neurodegeneration (CADN): development, validity and reliability of a bedside tool for dysphagia assessment. J Neurol. 2017 Jun;264(6):1107-17.

68 Coon EA, Sorenson EJ, Whitwell JL, Knopman DS, Josephs KA. Predicting survival in frontotemporal dementia with motor neuron disease. Neurology. 2011 May;76(22):1886-93.

69 Jankovic J, Friedman DI, Pirozzolo FJ, McCrary JA. Progressive supranuclear palsy: motor, neurobehavioral, and neuro-ophthalmic findings. Adv Neurol. 1990;53:293-304.

70 Burrell JR, Kiernan MC, Vucic S, Hodges JR. Motor neuron dysfunction in frontotemporal dementia. Brain. 2011 Sep;134(Pt 9):2582-94.

71 Mahapatra RK, Edwards MJ, Schott JM, Bhatia KP. Corticobasal degeneration. Lancet Neurol. 2004 Dec;3(12): 736-43.

72 Silbergleit AK, Feit H, Silbergleit R. Neurogenic stuttering in corticobasal ganglionic degeneration: A case report. J Neurolinguist. 2009;22(1):83-90.

73 Leiguarda R, Lees AJ, Merello M, Starkstein S, Marsden CD. The nature of apraxia in corticobasal degeneration. J Neurol Neurosurg Psychiatry. 1994 Apr;57(4):455-9. 
Lewis et al.: Review of Mealtime Difficulties following FTLD

74 Poole ML, Brodtmann A, Darby D, Vogel AP. Motor Speech Phenotypes of Frontotemporal Dementia, Primary Progressive Aphasia, and Progressive Apraxia of Speech. J Speech Lang Hear Res. 2017 Apr;60(4):897-911.

75 Kent RD. Research on speech motor control and its disorders: a review and prospective. J Commun Disord. 2000 Sep-Oct;33(5):391-427.

76 Shelley BP, Hodges JR, Kipps CM, Xuereb JH, Bak TH. Is the pathology of corticobasal syndrome predictable in life? Mov Disord. 2009 Aug;24(11):1593-9.

77 Gorno-Tempini ML, Murray RC, Rankin KP, Weiner MW, Miller BL. Clinical, cognitive and anatomical evolution from nonfluent progressive aphasia to corticobasal syndrome: a case report. Neurocase. 2004 Dec;10(6): 426-36.

78 Johnston BT, Castell JA, Stumacher S, Colcher A, Gideon RM, Li Q, et al. Comparison of swallowing function in Parkinson's disease and progressive supranuclear palsy. Mov Disord. 1997 May;12(3):322-7.

79 Leopold NA, Kagel MC. Dysphagia in progressive supranuclear palsy: radiologic features. Dysphagia. 1997; 12(3):140-3.

80 Warnecke T, Dziewas R. Swallowing in progressive supranuclear palsy and implications for nutrition. In: Martin CR, Preedy VR, editors. Diet and nutrition in dementia and cognitive decline. 1st ed. Elsevier; 2015. p. 1135-41.

81 Leopold NA, Kagel MC. Prepharyngeal dysphagia in Parkinson's disease. Dysphagia. 1996;11(1):14-22.

82 Maher ER, Lees AJ. The clinical features and natural history of the Steele-Richardson-Olszewski syndrome (progressive supranuclear palsy). Neurology. 1986 Jul;36(7):1005-8.

83 Warnecke T, Oelenberg S, Teismann I, Hamacher C, Lohmann H, Ringelstein EB, et al. Endoscopic characteristics and levodopa responsiveness of swallowing function in progressive supranuclear palsy. Mov Disord. 2010 Jul;25(9):1239-45.

84 Neumann S, Reich S, Buchholz D, Purcell L, Jones B. Progressive supranuclear palsy (PSP): characteristics of dysphagia in 14 patients. Dysphagia. 1996;11:164.

85 Boxer AL, Boeve BF. Frontotemporal dementia treatment: current symptomatic therapies and implications of recent genetic, biochemical, and neuroimaging studies. Alzheimer Dis Assoc Disord. 2007 Oct-Dec; 21(4):S79-87.

86 Ward C. Characteristics and symptom management of progressive supranuclear palsy: a multidisciplinary approach. J Neurosci Nurs. 2006 Aug;38(4):242-7.

87 Kortte KB, Rogalski EJ. Behavioural interventions for enhancing life participation in behavioural variant frontotemporal dementia and primary progressive aphasia. Int Rev Psychiatry. 2013 Apr;25(2):237-45.

88 Shinagawa S, Nakajima S, Plitman E, Graff-Guerrero A, Mimura M, Nakayama K, et al. Non-pharmacological management for patients with frontotemporal dementia: a systematic review. J Alzheimers Dis. 2015;45(1): 283-93.

89 Dickerson BC. Hodges' Frontotemporal Dementia. 2nd ed. Cambridge: Cambridge University Press; 2016.

90 Aiello M, Silani V, Rumiati RI. You stole my food! Eating alterations in frontotemporal dementia. Neurocase. 2016 Aug;22(4):400-9.

91 Malloy P, Grace J. A review of rating scales for measuring behavior change due to frontal systems damage. Cogn Behav Neurol. 2005 Mar;18(1):18-27.

92 Pfeifer L, Drobetz R, Fankhauser S, Mortby ME, Maercker A, Forstmeier S. Caregiver rating bias in mild cognitive impairment and mild Alzheimer's disease: impact of caregiver burden and depression on dyadic rating discrepancy across domains. Int Psychogeriatr. 2013 Aug;25(8):1345-55.

93 Pompanin S, Jelcic N, Cecchin D, Cagnin A. Impulse control disorders in frontotemporal dementia: spectrum of symptoms and response to treatment. Gen Hosp Psychiatry. 2014 Nov-Dec;36(6):760.e5-7.

94 Shinagawa S, Tsuno N, Nakayama K. Managing abnormal eating behaviours in frontotemporal lobar degeneration patients with topiramate. Psychogeriatrics. 2013 Mar;13(1):58-61.

95 Singam C, Walterfang M, Mocellin R, Evans A, Velakoulis D. Topiramate for abnormal eating behaviour in frontotemporal dementia. Behav Neurol. 2013 Jan;27(3):285-6.

96 Nestor PJ. Reversal of abnormal eating and drinking behaviour in a frontotemporal lobar degeneration patient using low-dose topiramate. J Neurol Neurosurg Psychiatry. 2012 Mar;83(3):349-50.

97 Cruz M, Marinho V, Fontenelle LF, Engelhardt E, Laks J. Topiramate may modulate alcohol abuse but not other compulsive behaviors in frontotemporal dementia: case report. Cogn Behav Neurol. 2008 Jun;21(2):104-6.

98 Lebert F, Stekke W, Hasenbroekx C, Pasquier F. Frontotemporal dementia: a randomised, controlled trial with trazodone. Dement Geriatr Cogn Disord. 2004;17(4):355-9.

99 Moretti R, Torre P, Antonello RM, Cazzato G, Bava A. Frontotemporal dementia: paroxetine as a possible treatment of behavior symptoms. A randomized, controlled, open 14-month study. Eur Neurol. 2003;49(1): 13-9. 